\title{
Regulamentação da vida no processo transexualizador brasileiro: uma análise sobre a política pública
}

\author{
Pablo Cardozo Rocon \\ Universidade Federal do Espírito Santo (UFES) \\ Francis Sodré \\ Universidade Federal do Espírito Santo (UFES)
}

\author{
Alexsandro Rodrigues \\ Universidade Federal do Espírito Santo (UFES)
}

\section{Regulamentação da vida no processo transexualizador brasileiro: uma análise sobre a política pública} Resumo: O processo transexualizador brasileiro tem sua história marcada pela judicialização da demanda, medicalização da experiência trans e regulamentação da vida pelo Estado. Esse programa tem se mostrado seletivo por meio de um diagnóstico referendado na matriz binária heterossexual para os gêneros como critério para entrada nos programas, não garantindo o acesso universal aos serviços em saúde. Foi realizada abordagem qualitativa com pesquisa documental. Os dados foram analisados a partir das categorias disciplina, biopolítica e biopoder de Foucault. Conclui que o processo transexualizador tem servido de dispositivo disciplinador sobre a população usuária, e equipamento para administração da vida trans na massa populacional. Assim, a seletividade pode ser compreendida como resultado da ação do Estado que, no exercício do biopoder, realiza um corte entre quem viverá ou morrerá.

Palavras-chave: Gênero. Pessoas Trans. Disciplina. Biopolítica. Biopoder.

\section{Regulation of Life in the Brazilian Transexualizing Process: an analysis of public policy}

Abstract: The history of the Brazilian transexualizing process is marked by legal resolution of the demand, medicalization of the trans experience and regulation of life by the state. This program has proven to be selective because of a diagnosis supported by the binary heterosexual matrix for genders, which serves as a criteria for entering the programs, which does not guarantee universal access to healthcare services. A qualitative approach was taken accompanied by document research. The data were analyzed based on Foucault's categories of discipline, biopolitics and biopower. It concludes that the transexualizing process has served as a disciplinary measure over the population that uses it, and as a mechanism for the administration of the trans life in the population. Thus, the selectivity can be understood as a result of the action of the state that, in the exercise of biopower, conducts a division between who will live and who will die.

Keywords: Gender. Trans people. Discipline. Biopolitics. Biopower. 


\section{Introdução}

As cirurgias de transgenitalização foram liberadas no Brasil a partir de 1997 por meio da resolução n.1482 do Conselho Federal de Medicina (CFM). Com o aprimoramento das técnicas cirúrgicas e a evolução dos protocolos terapêuticos, o CFM atualizou suas resoluções até a mais atual, a n. 1.955/2010. Em 2008, o Ministério da Saúde (MS) incorporou os procedimentos transgenitalizadores às mulheres transexuais ao Sistema Único de Saúde através da Portaria 1707/2008. Em 2013 o Ministério da Saúde ampliou o Processo Transexualizador do SUS através da Portaria 2803, e passou a contemplar as pessoas travestis e os homens transexuais nos serviços em saúde oferecidos.

Os estudos de Bento (2006; 2008; 2012) e Lionço (2009) evidenciaram que os programas transexualizadores têm apresentado barreiras ao acesso universal pela população trans - travestis, transexuais, transgêneros - nas normatizações regulamentadoras da organização desses programas e seu funcionamento. O diagnóstico de transexualismo, como condicionante do acesso aos serviços de saúde no Processo Transexualizador, tem sido apontado como uma dos principais impedimentos à universalização, excluindo pacientes do acesso por esse diagnóstico.

Outra observação necessária é o fato do conceito de transexualismo descrito pelas resoluções do Conselho Federal de Medicina (CFM) diferir do apresentando pela Organização Mundial da Saúde através da Classificação Estatística Internacional de Doenças e Problemas Relacionados à Saúde, o CID 10, além das pessoas travestis não aparecerem no texto do primeiro e serem apresentadas em categorias distintas das pessoas transexuais no segundo. Apesar das portarias do Ministério da Saúde condicionarem o acesso aos procedimentos transexualizadores ao diagnóstico, elas não são objetivas na definição dos parâmetros: CID 10 ou as resoluções do CFM. Bento (2006; 2008) ainda evidenciou que as equipes multiprofissionais do processo transexualizador têm fundamentado seus diagnósticos em concepções sociais e estereótipos sobre "ser ho$\mathrm{mem} / \mathrm{ser}$ mulher de verdade".

Esse artigo buscará construir uma genealogia histórica da regulamentação dos procedimentos transexualizadores no Brasil e identificar as marcas da judicialização e da medicalização como estratégias biopolíticas de regulamentação das vidas trans.

\section{Metodologia}

Foi utilizada metodologia qualitativa por meio de pesquisa documental e de caráter retrospectivo, no período de janeiro a março de 2015, nos sítios do Ministério da Saúde e do Conselho Federal de Medicina. Ainda compuseram o rol de documentos pesquisados: a Apelação Civil Pública, de 2007, julgada no Rio Grande do Sul, que decidiu pelo custeio dos procedimentos transexualizadores no âmbito do SUS; a Suspensão de Tutela Antecipada 185-2 Distrito Federal, contra o documento anteriormente citado, e julgado pela então Ministra do Supremo Tribunal Federal, Ellen Gracie; o artigo de Fragoso (1979), que analisa o processo criminal de Roberto Farina, médico que realizou a primeira cirurgia de transgenitalização no Brasil e foi acusado de crime de lesão corporal; e a Classificação Estatística Internacional de Doenças e Problemas Relacionados à Saúde, CID 10, nas categorias F064 (Transexualismo), F064.1 (Travestismo Bivalente) e F065,1 (Travestismo Fetichista). Para interpretação dos dados foi reconstruída genealogicamente uma história do processo transexualizador a partir dos documentos levantados, analisando-os a partir das categorias teóricas: disciplina, biopolítica e biopoder, de Foucault.

\section{Resultados e discussão}

A primeira cirurgia de mudança de sexo realizada no Brasil aconteceu na cidade de São Paulo, em 1971. Ela foi realizada pelo médico cirurgião plástico Roberto Farina, que foi interpelado judicialmente sob crime de lesão corporal (BENTO, 2008). Fragoso (1979, p. 9) analisou o caso Roberto Farina, alegando a inocência deste diante da acusação de lesão corporal sob a justificativa de cura: "lendo-se o depoimento dos médicos que assistiram o paciente antes da cirurgia, verifica-se que os cuidados necessários foram observados havendo uma espera de dois anos". Para ele, o referido acompanhamento por uma equipe médica atestou a necessidade da cirurgia a partir de um diagnóstico de transexualismo, e não deveria abrir precedentes para tal acusação. Fragoso (1979) defendeu Farina a partir da patologização da experiência transexual e, onde a existência de uma doença diagnosticada, seria o argumento necessário a justificar intervenção transexualizadora realizada pelo cirurgião plástico como terapêutica e não como lesão corporal. 
A autorização para realização das cirurgias transgenitalizadoras no Brasil aconteceu através da Resolução CFM 1482, de 1997, sob a ótica patologizadora. Essa normativa considerou as cirurgias de transgenitalização como etapa mais importante no tratamento de transexualismo com o propósito terapêutico específico de adequar a genitália ao sexo psíquico (CFM, 1997). Procedimentos inicialmente permitidos somente em hospitais universitários ou públicos adequados à pesquisa, uma vez que os procedimentos cirúrgicos de transgenitalização (mudança de sexo) foram autorizados sob caráter experimental. Importa destacar que a regulamentação desses procedimentos no Brasil aconteceu sob ótica terapêutica. O CFM partiu da medicalização das identidades de gênero Trans, tornando a patologização requisito ao acesso para normatizar os procedimentos transgenitalizadores.

Tabela 1 - Resoluções do Conselho Federal de Medicina

\begin{tabular}{|c|c|c|c|}
\hline & $\begin{array}{c}\text { RESOLUÇÃO CFM } \\
\text { 1482/1997 }\end{array}$ & $\begin{array}{l}\text { RESOLUÇÃO CFM } \\
1652 / 2002\end{array}$ & $\begin{array}{c}\text { RESOLUÇÃO CFM } \\
1955 / 2010\end{array}$ \\
\hline $\begin{array}{l}\text { Procedimentos comple- } \\
\text { mentares sobre gônadas e } \\
\text { caracteres sexuais secundá- } \\
\text { rios como tratamento }\end{array}$ & Experimental & $\begin{array}{l}\text { MTF* Autorizado }^{*} \\
\text { FTM* Experimental }^{*}\end{array}$ & Autorizado \\
\hline $\begin{array}{l}\text { Procedimento Cirúrgico } \\
\text { Neofaloplastia (construção } \\
\text { do pênis) }\end{array}$ & Experimental & Experimental & Experimental \\
\hline $\begin{array}{l}\text { Procedimento Cirúrgico } \\
\text { Neoculpovulvoplastia } \\
\text { (construção da vagina) }\end{array}$ & Experimental & Autorizado & Autorizado \\
\hline $\begin{array}{l}\text { Requisitos para entrada no } \\
\text { Programa }\end{array}$ & $\begin{array}{l}\text { Diagnóstico médico de } \\
\text { Transexualismo; Maior de } 21 \\
\text { anos; Ausência de caracterís- } \\
\text { ticas físicas inapropriadas à } \\
\text { cirurgia. }\end{array}$ & Idem Anterior & Idem Anterior \\
\hline Equipe Multiprofissional & $\begin{array}{l}\text { Psiquiatra, Cirurgião, Psicólo- } \\
\text { go, Assistente Social. }\end{array}$ & $\begin{array}{l}\text { Psiquiatra, Cirurgião, Psicólo- } \\
\text { go, Assistente Social, } \\
\text { Endocrinologista. }\end{array}$ & Idem Anterior \\
\hline $\begin{array}{l}\text { Critério/definição de } \\
\text { Transexualismo } \\
\text { (Transexualidade) }\end{array}$ & $\begin{array}{l}\text { Desconforto com o sexo } \\
\text { anatômico; Desejo expresso de } \\
\text { eliminar os genitais, perder as } \\
\text { características primárias e se- } \\
\text { cundárias do próprio sexo e ga- } \\
\text { nhar as do sexo oposto; Perma- } \\
\text { nência desse distúrbio de forma } \\
\text { contínua e consistente por, no } \\
\text { mínimo, } 2 \text { anos; Ausência de } \\
\text { outros transtornos mentais. }\end{array}$ & $\begin{array}{l}\text { Desconforto com o sexo natu- } \\
\text { ral; Desejo expresso de elimi- } \\
\text { nar os genitais, perder as ca- } \\
\text { racterísticas primárias e secun- } \\
\text { dárias do próprio sexo e ganhar } \\
\text { as do sexo oposto; Permanên- } \\
\text { cia desse distúrbio de forma } \\
\text { contínua e consistente por, no } \\
\text { mínimo, } 2 \text { anos; Ausência de } \\
\text { outros transtornos mentais. }\end{array}$ & $\begin{array}{l}\text { Desconforto com o sexo na- } \\
\text { tural; Desejo expresso de eli- } \\
\text { minar os genitais, perder as ca- } \\
\text { racterísticas primárias e se- } \\
\text { cundárias do próprio sexo e } \\
\text { ganhar as do sexo oposto; Per- } \\
\text { manência desse distúrbio de } \\
\text { forma contínua e consistente } \\
\text { por, no mínimo, } 2 \text { anos; Au- } \\
\text { sência transtornos mentais. }\end{array}$ \\
\hline $\begin{array}{l}\text { Definição de paciente } \\
\text { transexual }\end{array}$ & $\begin{array}{l}\text { Portador de desvio psicológi- } \\
\text { co permanente de identidade } \\
\text { sexual, com rejeição do } \\
\text { fenótipo e tendência ao auto } \\
\text { mutilação e/ou auto extermínio. }\end{array}$ & Idem Anterior & Idem Anterior \\
\hline Locais de Realização & $\begin{array}{l}\text { Hospitais Universitários ou } \\
\text { Públicos adequados à pesqui- } \\
\text { sa. }\end{array}$ & $\begin{array}{l}\text { FTM Idem Anterior } \\
\text { MTF Hospitais Públicos ou } \\
\text { Privados independente da ati- } \\
\text { vidade com pesquisa. }\end{array}$ & $\begin{array}{l}\text { Estabelecimentos que con- } \\
\text { templem integralmente os re- } \\
\text { quisitos da presente resolução. }\end{array}$ \\
\hline
\end{tabular}

Fonte: Resolução CFM 1482/1997; Resolução CFM 1652/2002; Resolução CFM 1955/2010.

Obs.: *MTF: Male to Female (Masculino para Feminino); **FTM: Female to Male (Feminino para masculino). 
Segundo Lionço (2009), em 2001 houve uma ação do Ministério Público Federal para inclusão dos procedimentos transgenitalizadores na tabela do SUS nos termos da Resolução CFM 1482/97. Além da judicialização da demanda das pessoas trans, a autora relatou que nesse contexto foi reafirmado a patologização das identidades de gênero Trans como justificativa à inclusão desses procedimentos na tabela de pagamento do SUS. Em 2002, o CFM revogou sua normativa anterior através da resolução 1652/2002. Ao considerar bons os resultados cirúrgicos das neoculpovulvoplastias e procedimentos sobre gônadas e caracteres sexuais secundários do tipo MTF (masculino para feminino), retirou o caráter experimental desse procedimento, autorizando sua realização em hospitais independente das atividades com pesquisa. Contudo, as cirurgias do tipo neofaloplastia e procedimentos sobre gônadas e caracteres sexuais secundários do tipo FTM (feminino para masculino) foram mantidos sob caráter experimental sob alegação de dificuldades técnicas para obtenção de bons resultados, permanecendo restritas aos hospitais universitários e públicos adequados às pesquisas. A nova resolução ainda acrescentou o médico endocrinologista à equipe multiprofissional.

Em 2006 aconteceu uma reunião do Comité Técnico Saúde da População GLTB denominada Processo Transexualizador. Foi um marco importante na superação do entendimento sobre a atenção à saúde Trans restrita aos procedimentos médico-cirúrgicos implicados na transgenitalização. Houve apontamentos críticos em relação à patologização e a centralidade das metas terapêuticas aos procedimentos médicos-cirúrgicos. As cirurgias "passaram a ser compreendidas como parte ou não do processo transexualizador, e a discussão superou o viés medicalizador e correcional para o foco na garantia à saúde integral" (LIONÇO, 2009, p. 51).

Em 2007, a Terceira Turma do TRF da $4^{a}$ Região (Rio Grande do Sul) decidiu pelo custeio através do SUS das cirurgias de transgenitalização em casos de transexualidade. A Advocacia-Geral da União entrou com pedido de Suspenção de Tutela Antecipada contra essa decisão no Supremo Tribula Federal (STF). Em dezembro de 2007, a então Ministra do STF Ellen Gracie, decidiu pela suspenção da decisão do TRF que havia determinado à União um prazo de 30 dias para tomar todas as medidas necessárias para realização desse procedimento no SUS. Em seu julgamento, Ellen Gracie disse não desconhecer o sofrimento dos "pacientes portadores de transexualismo (patologia devidamente reconhecida pela Organização Mundial de Saúde: CID10 F64.0)" (BRASIL, 2007) e que, nesse sentido, se submetem aos programas de transexualização com objetivo de realizar a cirurgia de transgenitalização.

O Ministério da Saúde, em 2008, por meio da Portaria GM 1707/2008, instituiu o Processo Transexualizador do SUS, determinando que as condições de funcionamento devessem seguir os critérios estabelecidos pela Resolução CFM 1652/2002. A Portaria reconheceu que "a orientação sexual e a identidade de gênero são fatores reconhecidos pelo Ministério da Saúde como determinantes e condicionantes da situação de saúde" (BRASIL, 2008). Apesar desse reconhecimento que aponta a violência, a violação dos direitos, etc., como causadores de agravos a saúde da população LGBT, ao definir os critérios para acesso aos serviços em saúde oferecidos pelo Processo Transexualizador do SUS, a referida portaria insistiu na manutenção do diagnóstico de transexualismo, com base no CID-10, que exprime a ideia de que os tratamentos em saúde para a população trans devem privilegiar as mudanças corporais através do tratamento cirúrgico e/ou hormonioterapia. Essa portaria contemplou apenas as mulheres transexuais. As normativas justificaram a não inclusão dos homens transexuais na caracterização dos procedimentos de neofaloplastia como experimentais. Entretanto, também não incluiu cirurgias de mastectomia e histerectomia, nem mesmo autorizou a hormonioterapia, que também poderia ter sido estendida as pessoas travestis e aos últimos.

O CFM, em 2010, reatualizou sua normatização a partir da Resolução 1955/2010 que autorizou que as cirurgias de transgenitalização, neoculpovulvoplastia ou neofaloplastia e os procedimentos complementares sobre gônadas e caracteres sexuais secundários, sejam realizados em hospitais públicos ou privados que contemplem os requisitos da referida resolução. Houve em 2013 uma tentativa de redefinição do Processo Transexualizador do SUS pelo Ministério da Saúde através da Portaria 859/2013. Essa portaria trouxe muitas novidades, como a inclusão das pessoas travestis e homens transexuais nos serviços oferecidos, a redução da idade para acompanhamento clínico e hormonioterapia de 21 anos para 16 anos e para realização de cirurgias de 21 para 18 anos. Inaugurou ainda um serviço de acompanhamento exclusivamente clínico a ser realizado a partir dos cinco anos, conforme Tabela 2, acima. Não houve a inclusão das cirurgias do tipo neofaloplastia, ofertando os procedimentos cirúrgicos mastectomia e histerectomia aos homens transexuais. O texto manteve o diagnóstico como critério seletivo, no entanto, não definiu os fundamentos desse diagnóstico, diferentemente da portaria anterior que se pautava pelo CID 10 e pela Resolução CFM 1652/2002. As pessoas Travestis não se enquadram nos critérios estabelecidos pelo Conselho Federal de Medicina, e no CID 10 são descritas em duas categorias distintas entre si F064.1 (Travestismo Bivalente) e F065.1 (Travestismo Fetichista) com descrições diferenciadas da utilizada para Transexualismo. Sobre os tipos de travestismos supracitados: 
Tabela 2 - Portarias Ministerias sobre o processo transexualizador do SUS

\begin{tabular}{|c|c|c|c|}
\hline & $\begin{array}{c}\text { PORTARIA GM/MS } \\
\text { 1707/2008 } \\
457 / 2008 *\end{array}$ & $\begin{array}{c}\text { PORTARIA } \\
\text { GM/MS 859/2013** }\end{array}$ & $\begin{array}{c}\text { PORTARIA } \\
\text { GM/MS 2803/2013 }\end{array}$ \\
\hline $\begin{array}{l}\text { Usuários/as } \\
\text { Atendidos/as }\end{array}$ & Mulheres Transexuais & $\begin{array}{l}\text { Mulheres Transexuais } \\
\text { Homens Transexuais } \\
\text { Travestis }\end{array}$ & \\
\hline $\begin{array}{l}\text { Requisitos para Realização } \\
\text { de Cirurgias }\end{array}$ & $\begin{array}{l}\text { Em conformidade com a Re- } \\
\text { solução CFM 1652/2002. }\end{array}$ & $\begin{array}{l}18 \text { anos, acompanhamento } \\
\text { prévio de mínimo de } 2 \text { anos, } \\
\text { com diagnóstico. }\end{array}$ & \\
\hline $\begin{array}{l}\text { Procedimentos Cirúrgicos } \\
\text { complementares sobre } \\
\text { gônadas e caracteres sexu- } \\
\text { ais secundários realizados }\end{array}$ & $\begin{array}{l}\text { MTF}^{1} \text { : Retirada do pomo de } \\
\text { Adão e Alongamento das cor- } \\
\text { das vocais. }\end{array}$ & $\begin{array}{l}\text { MTF: Retirada do pomo de } \\
\text { Adão } \\
\text { e Cirurgias complementares }{ }^{3} \text {. } \\
\text { FTM }^{2} \text { : Mastectomia e } \\
\text { Histerectomia }\end{array}$ & \\
\hline $\begin{array}{l}\text { Procedimento Cirúrgico } \\
\text { Neofaloplastia (construção } \\
\text { do pênis) }\end{array}$ & Não Realiza & Não Realiza & \\
\hline $\begin{array}{l}\text { Procedimento Cirúrgico } \\
\text { Neoculpovulvoplastia } \\
\text { (construção da vagina) }\end{array}$ & Autorizado & Autorizado & \\
\hline $\begin{array}{l}\text { A c o m p a n h a m e n t o } \\
\text { Multiprofissional Pré e Pós } \\
\text { Operatório }\end{array}$ & Período de 2 anos. & $\begin{array}{l}\text { Após o diagnóstico. Idade mí- } \\
\text { nima de } 16 \text { anos; Período mí- } \\
\text { nimo de } 2 \text { anos no pré e máxi- } \\
\text { mo de } 1 \text { ano pós. }\end{array}$ & \\
\hline $\begin{array}{l}\text { Requisitos para Realização } \\
\text { de Terapia Hormonal }\end{array}$ & $\begin{array}{l}\text { Em conformidade com a Re- } \\
\text { solução CFM 1652/2002. }\end{array}$ & $\begin{array}{l}16 \text { anos e diagnóstico no pro- } \\
\text { cesso transexualizador. }\end{array}$ & \\
\hline $\begin{array}{l}\text { Requisitos para Acompa- } \\
\text { nhamento exclusivamente } \\
\text { Clínico }^{4}\end{array}$ & Não Realiza & 5 anos & \\
\hline $\begin{array}{l}\text { Equipe Multiprofissional } \\
\text { Mínima }\end{array}$ & $\begin{array}{l}\text { Equipe mínima de saúde: } \\
\text { Médico Cirurgião, Anestesio- } \\
\text { logista, Enfermagem. } \\
\text { Equipe Multiprofissional: } \\
\text { Psiquiatra, Endocrinologista, } \\
\text { Psicólogo e Assistente So- } \\
\text { cial. }\end{array}$ & $\begin{array}{l}\text { Ambulatorial: Psiquiatra ou } \\
\text { Psicólogo, Endocrinologista } \\
\text { ou Clínico Geral, Assistente } \\
\text { Social, Enfermeiro. } \\
\text { Hospitalar: Urologista ou gi- } \\
\text { necologista ou cirurgião plás- } \\
\text { tico, Equipe de enfermagem, } \\
\text { Endocrinologista, Assistente } \\
\text { Social, Psiquiatra ou Psicó- } \\
\text { logo. }\end{array}$ & \\
\hline $\begin{array}{l}\text { Parâmetros para Diagnós- } \\
\text { tico de Transexualismo }\end{array}$ & $\begin{array}{l}\text { Em conformidade com a Re- } \\
\text { solução CFM 1652/2002. }\end{array}$ & Não informa. & \\
\hline Locais de Realização & $\begin{array}{l}\text { Hospitais Credenciados/habi- } \\
\text { litados junto ao Ministério da } \\
\text { Saúde. }\end{array}$ & Idem Anterior. & \\
\hline
\end{tabular}

Fonte: Portaria GM/MS 1707/2008; Portaria GM/MS 457/2008, Portaria GM/MS 859/2013; Portaria GM/MS 2803/2013.

Obs.: *Complementa a Portaria 1707/2008; ** Efeitos suspensos pela Portaria 1579/2013; 1. MTF: Male to Female (Masculino para Feminino); 2. FTM: Female to Male (Feminino para masculino); 3. Reconstrução da neovagina realizada, meatotomia, meatoplastia, 
cirurgia estética para correções complementares dos grandes lábios, pequenos lábios e clitóris e tratamento de deiscências e fístulectomia. 4. Acompanhamento no Processo Transexualizador com atendimento mensal por equipe multiprofissional, diferente do acompanhamento exclusivo das etapas no pré ou pós operatório.

Este termo designa o fato de usar vestimentas do sexo oposto durante uma parte de sua existência, de modo a satisfazer a experiência temporária de pertencer ao sexo oposto, mas sem desejo de alteração sexual mais permanente ou de uma transformação cirúrgica; a mudança de vestimenta não se acompanha de excitação sexual. Transtorno de identidade sexual no adulto ou adolescente, tipo não-transexual. Vestir roupas do sexo oposto, principalmente com o objetivo de obter excitação sexual e de criar a aparência de pessoa do sexo oposto. O travestismo fetichista se distingue do travestismo transexual pela sua associação clara com uma excitação sexual e pela necessidade de se remover as roupas uma vez que o orgasmo ocorra e haja declínio da excitação sexual. Pode ocorrer como fase preliminar no desenvolvimento do transexualismo. Fetichismo com travestismo (OMS, 2008).

Essa portaria teve curta vigência, sendo revogada pela Portaria 1579/2013. Ainda em 2013, o Ministério da Saúde publicou a Portaria 2803/2013, em cumprimento a uma Ação Civil Pública de 13 de setembro de 2013 que determinou ao Ministério da Saúde, em um prazo de 30 dias, tomar todas as medidas necessárias à garantia da realização de todos os procedimentos médicos "para garantir a cirurgia de transgenitalização e a readequação sexual no Processo Transexualizador" nos termos da Resolução CFM n 1.652/2012 (BRASIL, 2013a). A nova normatização ampliou as idades para todos os procedimentos: hormonioterapia de 16 para 18 anos, a realização das cirurgias de 18 para 21 anos e o acompanhamento exclusivamente clínico, inserido pela portaria anterior, teve a idade ampliada de cinco para 18 anos. A Portaria MS 2803/2013 adicionou as cirurgias de neofaloplastia e outras cirurgias (vaginectomia e neofaloplastia com implante de próteses penianas e testiculares, clitoroplastia e cirurgia de cordas vocais em pacientes em readequação para o fenótipo masculino) para homens transexuais, mantendo o caráter experimental e os critérios estabelecidos na Resolução CFM 1955/2010. Acrescentou também as cirurgias para implante de prótese mamária. A normativa incluiu as pessoas travestis, no entanto, manteve o diagnóstico como condicionante ao acesso à hormonioterapia, diagnóstico, como dito anteriormente, que não contempla as pessoas travestis, conforme Tabela 2, acima.

\section{Medicalização das identidades e judicialização da saúde trans}

A história dos procedimentos transexualizadores no Brasil é marcada pela judicialização e medicalização da demanda. Assim, cabe questionar o que tem subsidiado o entendimento sobre transexualidade pelos poderes médico-jurídico expresso nas normativas, bem como as consequências produzidas por esse entendimento. As normatizações têm sido eficientes na garantia do acesso aos serviços de saúde a todas as pessoas Trans? Porque a patologização das identidades trans é requisito para acesso aos serviços do SUS?

Ao observar a Tabela 1 percebe-se que não houve alterações na definição de transexualismo e em seus critérios entre a primeira e a última resolução do CFM. As portarias ministeriais que regulamentaram o processo transexualizador no SUS ora se orientaram pelas resoluções CFM, ora pela CID-10, ou não deixaram claro. Contudo, ao comprar as definições de transexualismo vê-se que, para o CFM (2010) é: "portador de desvio psicológico permanente de identidade sexual, com rejeição do fenótipo e tendência ao auto mutilação e/ou auto extermínio". Segundo o CID- 10 (OMS, 2008), “Trata-se de um desejo de viver e ser aceito enquanto pessoa do sexo oposto. Este desejo se acompanha em geral de um sentimento de mal estar ou de inadaptação por referência a seu próprio sexo anatômico e do desejo de submeter-se a uma intervenção cirúrgica ou a um tratamento hormonal a fim de tornar seu corpo tão conforme quanto possível ao sexo desejado".

O CFM elaborou o paciente transexual como doente mental e potencial suicida, e a CID-10 apresenta uma definição que traduz um paciente em busca da construção de um corpo que lhes corresponda ao gênero binário. Ambas as definições reafirmam a impossibilidade de uma vida no gênero fora das fronteiras do binarismo, onde os corpos são lidos a partir de suas genitálias, com a masculinidade referendada no pênis e a feminilidade na vagina (BENTO, 2012). O gênero binário determina lugares aos indivíduos nas relações sociais a partir dos pressupostos supracitados, produzindo as diferenças de gostos, habilidades, vestimentas, estéticas corporais, emprego, renda etc. para homens e mulheres, numa lógica: pênis, logo homem, logo masculino versus vagina, logo mulher, logo feminino, conduzidos à complementariedade a partir da heterossexualidade (BENTO, 2006; 2008; 2012). A patologização dos corpos e a medicalização das experiências identitárias trans podem ser compreendidas como efeitos do binarismo dos gêneros sobre a vida. Segundo Canguilhem (2011,p. 77) "curar 
é fazer voltar à norma uma função ou organismo que dela tenha se afastado". O diagnóstico médico conjuga normas e valores estabelecidos em sociedade num dado memento histórico, produzindo as compreensões sobre normal versus patológico. Analisar os significados de saúde e doença permeados pelas normas socioculturais e históricas sobre gênero e sexualidade, permite compreender a produção, na modernidade ocidental, do transexualismo e dos travestismos.

Analisando as tabelas 1 e 2 junto aos demais documentos apresentados a partir de Canguilhem (2011, p. 77), evidencia-se a tendência à normalização dos/as pacientes trans ao gênero binário, na medida em que busca desvendar, descrever e detalhar as anormalidades, através de um diagnóstico, cujas referencias não se restringirão à variáveis anatômicas, fisiológicas e patológicas, mas também à "representação comum da norma em um meio social em dado momento". Não existirá diagnóstico a-histórico, portanto, os sinais e sintomas de uma doença carregarão os significados produzidos nas relações sociais, "pois o indivíduo é doente segundo a classificação de sua sociedade e de acordo com os critérios e modalidades que ela fixa" (FERREIRA, 1994, p. 103). Nesse entendimento, a patologização das identidades Trans representará uma ação normalizadora sobre corpos que se desviam das normas sociais estabelecidas para a vida nos gêneros.

As tabelas 1 e 2 apresentam as orientações dadas pelas normatizações ao processo de trabalho das equipes multiprofissionais envolvidas na seleção e acompanhamento dos pacientes no processo transexualizador, apresentando tanto os critérios para entrada nesse programa quanto para definição do diagnóstico que foram produzidos e compõem o que Bento (2006) e Arán et al. (2008) chamaram dispositivo da transexualidade.

A busca constante por diferenciar transexuais de travestis, gays e lésbicas, na década de 1950, motivou uma série de publicações que objetivaram defender a existência de um "fenômeno transexual" com a apropriação desse pela medicina (BENTO, 2006; ARÁN et al., 2008). Supondo que o problema está no indivíduo e não no binarismo heterossexual para os gêneros (BENTO, 2006), o diagnóstico de transexualismo é definido por uma "concepção normativa, seja do sistema sexo-gênero, seja do dispositivo diferença sexual" fundada "numa matriz binária heterossexual que se converte em sistema regulador da sexualidade e da subjetividade" (ARÁN et al. 2008, p. 72). Criou-se uma semiologia do gênero para desvendar o transexual verdadeiro ou transexual oficial (ALMEIDA; MURTA, 2013). Segundo Bento, (2008, p.17), espera-se do transexual oficial a reprodução de comportamentos, desejos etc. que condizem às "definições do que seja um/a homem/mulher de 'verdade' se refletem e emergem nas definições do que seja um/a transexual de verdade". Mas não só. As resoluções do CFM (Tabela 1) também esperam a rejeição ao próprio corpo com tendência ao suicídio ou automutilação. Dessa forma: "O único mapa que guia o olhar médico e dos membros da equipe são as verdades estabelecidas socialmente para os gêneros. Não existe um só átomo de neutralidade. Estamos diante de um poderoso discurso que tem como finalidade manter os gêneros prisioneiros à diferença sexual" (BENTO, 2008, p.17). As pessoas trans, ao não reproduzirem a matriz binária para os gêneros, vão sendo construídas anormais, doentes e ininteligíveis. Por um processo de desumanização tenderão a dois caminhos: a abjeção ou a medicalização. Todavia, esses caminhos nem sempre são passíveis de escolha, uma vez que seguir pelo segundo implicará na autorização pela equipe de saúde envolvida no diagnóstico de transexualismo. Dessa forma, a patologização impede o acesso universal dos pacientes ao Processo Transexualizador do SUS ao criar um acesso seletivo a partir do diagnóstico, não respeitando a diversidade existente na população usuária, evidenciada nos estudos de Pelúcio (2005), Bento (2006), Almeida (2012), Teixeira (2014), dentre outros.

\section{Regulamentação da vida e Processo Transexualizador}

O processo transexualizador pode ser interpretado como estratégia biopolítica de controle sobre os corpos trans, operando por mecanismos disciplinares empenhados em normalizar e treinar os corpos para a vida no binarismo heterossexual para os gêneros, e em função do controle e administração dos corpos chamados anormais no nível da população pela regulamentação da vida. Segundo Foucault (1999, p. 289):

A disciplina tenta reger a multiplicidade dos homens na medida em que essa multiplicidade pode e deve redundar em corpos individuais que devem ser vigiados, treinados, utilizados, eventualmente punidos. E depois, a nova tecnologia que se instala se dirige à multiplicidade dos homens, não na medida em que eles se resumem a corpos, mas na medida em que ela forma, ao contrário, a massa global, afetada por processos de conjunto que são próprios da vida, que são processos como o nascimento, a morte, a produção etc. [...] Depois da anátomo-política do corpo humano, instaurada no decorrer do século 18, vemos aparecer, no fim do mesmo século, algo que já não é uma anátomo-política do corpo humano, mas que eu chamaria de uma biopolítica da espécie humana. 
A diferença entre poder disciplinar e biopoder está no detalhamento e na escala de ação. Enquanto a disciplina investe na minuciosidade, na separação dos corpos, no corpo-indivíduo, o biopoder se lança ao corpo-espécie, na escala da população. A matriz binária e heterossexual para os gêneros amplia as capacidades de regulamentação da vida pelo biopoder, servindo às múltiplas estratégias que "procuram intervir nos agrupamentos humanos, buscando regular taxas de nascimento e mortalidade, condições de saúde, expectativa de vida, deslocamentos geográficos etc." (Louro, 2014, p. 45). Para Foucault (2013), poder disciplinar e biopoder têm como propósito controlar e modificar os processos de vida, ações que podem ser encontradas no processo transexualizador.

As normativas (tabela 1 e 2) sobre o processo transexualizador estabelecem preceitos para seleção e acompanhamento dos pacientes que redundarão em ações disciplinares, uma vez que o acesso e a permanência no interior desse programa requer a reprodução das normas de gênero que servirão de passaporte ante os diagnósticos médico-psicológicos. Nele, os corpos serão desmontados, rearticulados e treinados à "normalidade" da vida no gênero a partir das hormonioterapias, cirurgias plásticas, acompanhamento clínico-psicológico e social, e da cirurgia de transgenitalização, procedimento considerado "fechar o ciclo" das transformações.

A existência na condição de humano está diretamen-

A seletividade do Processo Transexualizador pode ser analisada como contradição inerente à regulamentação das vidas trans pelo Estado que, no corte entre vida e morte no exercício do biopoder, separará os dignos de acesso. te ligada ao reconhecimento do sexo e gênero (ARÁN et al., 2008). As normatizações do processo transexualizador conduzem ao entendimento de que todas as pessoas transexuais odeiam seus corpos, tendem ao suicídio e, portanto, buscam a readequação de seus corpos, gêneros e sexualidades as normas pra esses estabelecidas, quando na verdade: "os/as transexuais buscam com as cirurgias reparadoras é o reconhecimento de seu pertencimento à humanidade A humanidade só existe em gêneros, e o gênero só é reconhecível, só ganha vida e adquire inteligibilidade, segundo as normas de gênero, em corpos-homens e corpos-mulheres" (BENTO, 2006, p. 230).

O hospital, lugar de funcionamento dos processos transexualizadores, será um privilegiado equipamento de operacionalização da regulamentação da vida, onde "o indivíduo e a população são dados simultaneamente como objetos de saber e alvos de intervenção da medicina, graças à tecnologia hospitalar" (FOUCAULT, 2006, p. 111). Essa medicina, como estratégia biopolítica, funcionará ao controle da sociedade sobre os indivíduos. Nesses termos, o processo transexualizador, pode ser compreendido como engrenagem da maquinaria hospital, envolvida na administração da vida desde os corpos-indivíduos ao nível da população como massa. Segundo Bento (2008, p. 68): "No hospital realiza-se um trabalho de 'assepsia de gênero', retirando tudo que sugira ambiguidades e possa pôr em xeque um dos pilares fundantes das normas de gênero: o dimorfismo natural dos gêneros".

Disciplina e biopoder agem de forma articulada forjando o que Foucault (1999) chamou de sociedade de normalização, segundo o qual é "efeito histórico de uma tecnologia de poder centrada na vida" (FOUCAULT, 2013, p. 157). Uma sociedade pautada na regulamentação da vida, na criação de regras jurídicas, morais, éticas, estéticas, sobre os mais variados temas que atravessam a vida, dentre eles, gênero e sexualidade. Através do biopoder, o Estado pode exercer um corte entre quem viverá ou morrerá, por um poder de fazer viver ou deixar morrer, sobre as suas populações (FOUCAULT, 1999). Sobre a população trans, na medida em que essas vidas subvertem as normas sociais para gênero e sexualidade, são classificadas como anormais, doentes ou degeneradas, como ameaça à preservação da vida da população. Somente pela prerrogativa de defender e ampliar a vida é que o poder terá acesso ao corpo para conduzi-lo à morte ou à vida (FOUCAULT, 2013). O Estado do biopoder deixa morrer pelo diagnóstico do processo transexualizador ao passo que não elimina os impedimentos, às dezenas de pessoas trans, acessarem com autonomia e liberdade os serviços de saúde para realizarem as modificações corporais desejadas, restando-lhes o risco de morte pelo uso, sem acompanhamento médico, de hormônios e pelas aplicações de silicone industrial.

\section{Considerações Finais}

A trajetória do processo transexualizador brasileiro permite destacar três marcos: o processo criminal respondido por Roberto Farina, em 1971, como sanção pela intervenção sobre um corpo sem autorização; a 
regulamentação como procedimento médico, em 1997, pelo CFM, normalizando o exercício médico sobre os corpos trans a partir da medicalização; a transformação em política pública, em 2008, com a criação do Processo Transexualizador do SUS, marcada pela judicialização da demanda, a articulação entre movimentos sociais e o poder público na discussão e pressão do Estado, pela normalização do exercício profissional e a medicalização das vidas trans por dentro dos equipamentos biopolíticos estatais.

A patologização das identidades trans pode ser compreendida como desdobramentos de tecnologias sobre o sexo produzidas a partir de poderes e saberes médicos sobre os corpos que, a partir dos séculos 17 e 18, foram diferenciando os corpos de forma binária e propondo uma coerência entre sexo e gênero pela heterossexualidade (BENTO, 2006; ARÁN et al., 2008; LAQUEUR, 2001). Todavia, quando a vida trans não se enquadrar nas categorias de gênero disponíveis, sofre com limitações no acesso à saúde por não apresentarem as características esperadas no processo de diagnóstico das identidades de gênero. A seletividade do Processo Transexualizador pode ser analisada como contradição inerente à regulamentação das vidas trans pelo Estado que, no corte entre vida e morte no exercício do biopoder, separará os dignos de acesso. Os Estudos de Bento $(2006 ; 2008$; 2012) permitem sugerir que os corpos que melhor reproduzem, na estética corporal e nas performances de gênero, a matriz binária e heterossexual para os gêneros serão vistos potenciais candidatos ao fazer viver pelo acesso aos serviços em saúde oferecidos. Assim, como pacientes em parada cardíaca, que requerem condições físicas que proporcionem a ausência de complicações para que as manobras de ressurreição sejam efetivas, os corpos trans são cobrados de "ausência de características físicas inapropriadas" (CFM, 2010). A patologização das identidades trans, ao tornar seletiva a entrada no processo transexualizador, opõe-se a proposta da universalidade e equidade no SUS. Seguindo na análise da vida trans numa perspectiva de totalidade histórica, a patologização se configurará numa determinação que, além de raiz de restrições sociais e estigma, reforçará a condição de exclusão social dessa população (ARÁN et al., 2009).

\section{Referências}

ALMEIDA, G. 'Homens trans': novos matizes na aquarela das masculinidades? Estudos Feministas, Florianópolis, v. 20, n. 2 , p. 513 $523,2012$.

, G.; MURTA, D. Reflexões sobre a possibilidade da despatologização da transexualidade e a necessidade da assistência integral à saúde de transexuais no Brasil. Revista Latinoamericana Sexualidad, Salud y Sociedad, Rio de Janeiro, n. 14, p. 380-407, ago. 2013. ARÁN, M.; MURTA, D.; LIONÇO, T. Transexualidade e Saúde Pública no Brasil. Ciência saúde coletiva, v. 14, n. 4, p. 1141 -1149. 2009.

, M.; ZAIDHAFT, S.; DANIELA, M. Transexualidade: corpo, subjetividade e saúde coletiva. Psicologia e Sociedade, v. 20, n. 1, p.70-79, 2008 .

BENTO, B. A (re)invenção do corpo: sexualidade e gênero na experiência transexual. Rio de Janeiro: Garamond, 2006.

, B. O que é transexualidade. São Paulo: Brasiliense, 2008.

, B. Sexualidade e experiências trans: do hospital à alcova. Ciência e Saúde Coletiva, Rio de Janeiro, p. 2655-2664, 2012.

BRASIL. Ministério da Saúde. Institui, no âmbito do Sistema Único de Saúde (SUS), o Processo Transexualizador, a ser implantado nas unidades federadas, respeitadas as competências das três esferas de gestão. Portaria n. 1.707, de 18 de agosto de 2008 . Disponível em: http://bvsms.saude.gov.br/bvs/saudelegis/gm/2008/prt1707_18_08_2008.html. Acesso em: 03 Mai. 2015.

. Ministério da Saúde. Portaria n. 457, de 19 de agosto de 2008. Disponível em: <http://bvsms.saude.gov.br/bvs/saudelegis/sas/ 2008/prt0457_19_08_2008.html> Acesso em: 03 Mai. 2015.

. Ministério da Saúde. Redefine e amplia o Processo Transexualizador no Sistema Único de Saúde (SUS). Portaria n. 2.803, de 19 de novembro de 2013a. Disponível em: <http://bvsms.saude.gov.br/bvs/saudelegis/gm/2013/prt2803_19_11_2013.html>. Acesso em: 03 Mai. 2015.

. Ministério da Saúde. Redefine e amplia o Processo Transexualizador no Sistema Único de Saúde - SUS. Portaria n. 859, de 30 de julho de 2013b. Disponível em: <http://bvsms.saude.gov.br/bvs/saudelegis/sas/2013/prt0859_30_07_2013.html> Acesso em: 03 Mai. 2015.

. Ministério da Saúde. Suspende os efeitos da Portaria n. 859/SAS/MS de 30 de julho de 2013. Portaria n. 1.579, de 31 de julho de 2013c. Disponível em: < http://bvsms.saude.gov.br/bvs/saudelegis/gm/2013/prt1579_31_07_2013.html>. Acesso em: 03 Mai. 2015.

. Supremo Tribunal Federal. Suspensão de tutela antecipada 185-2 distrito federal. Disponível em: < http://www.stf.jus.br/ arquivo/cms/noticiaNoticiaStf/anexo/STA185.pdf> Acesso em: 20 Abr. 2015.

CANGUILHEM, G. O normal e o patológico. Rio de Janeiro: Forense Universitária, 2011.

CONSELHO FEDERAL DE MEDICINA. Resolução n. 1.482, de 19 de setembro de 1997. Autoriza a título experimental, a realização de cirurgia de transgenitalização do tipo neocolpovulvoplastia, neofaloplastia e ou procedimentos complementares sobre gônadas e caracteres sexuais secundários com o tratamento dos casos de transexualismo. Disponível em: < http://www.portalmedico.org.br/ resolucoes/CFM/1997/1482_1997.htm>. Acesso em: 03 Mai. 2015. 
Resolução n. 1.652, de 2 de dezembro de 2002. Dispõe sobre a cirurgia de transgenitalismo e revoga a resolução CFM n. 1.482, de 19 de setembro de 1997. Disponível em: < http://www.portalmedico.org.br/resolucoes/CFM/2002/1652_2002.htm>.Acesso em: 03 Mai. 2015.

. Resolução n. 1.955, de 3 de setembro de 2010. Dispõe sobre a cirurgia de transgenitalismo e revoga a Resolução CFM n. 1.652, de 2 de dezembro de 2002. Disponível em: < http://www.portalmedico.org.br/resolucoes/CFM/2010/1955_2010.htm>. Acesso em: 03 Mai. 2015.

FERREIRA, J. O corpo signo. In ALVES, P.C.; MINAYO, M.C.S. (Org.). Saúde e Doença: Um olhar antropológico. Rio de Janeiro: Fiocruz, 1994.

FOUCAULT, M. Em defesa da sociedade: curso no Collège de France (1975-1976). Tradução Maria Ermantina Galvão. São Paulo: Martins Fontes, 1999.

História da sexualidade I: a vontade de saber. Tradução de Maria Thereza da Costa Albuquerque e J. A. Guilhon Albuquerque. São Paulo: Graal, 2013.

. Microfísica do poder. Tradução de Roberto. Machado. São Paulo: Graal, 2006.

FRAGOSO, H. C. Transexualismo: cirurgia: lesão corporal. Revista de Direito Penal, Rio de janeiro, v. 25, p. 25-34, 1979. Disponível em <http://www.fragoso.com.br/eng/arq_pdf/heleno_artigos/arquivo27.pdf>. Acesso em: 20 Abri. 2015.

LAQUEUR, T. Inventando o sexo: corpo e gênero dos gregos a Freud. Rio de Janeiro: Relume Dumará, 2001.

LIONÇO, T. Atenção integral à saúde e diversidade sexual no Processo Transexualizador do SUS. Physis, Rio de Janeiro, v. 19, n. 1, p. 43-63, 2009.

LOURO, G. L. Gênero, sexualidade e educação: uma perspectiva pós-estruturalista. Rio de Janeiro: Vozes, 2014.

ORGANIZAÇÃO MUNDIAL DA SAÚDE. Classificação Estatística Internacional de Doenças e Problemas Relacionados à Saúde CID 10. Décima Revisão, vol. I 2008. Disponível em <http://www.datasus.gov.br/cid10/V2008/cid10.htm> Acesso em: 03 mai. 2015. PELÚCIO, L. "Toda quebrada na plástica”: corporalidade e construção de gênero entre travestis paulistas. Revista de Antropologia Social, Campos, v. 6, n. 1-2, p. 97-112. 2005.

TEIXEIRA, F.B. Histórias que não têm era uma vez: as (in)certezas da transexualidade, Revista de Estudos Feministas, Florianópolis, v. 20 , n. 2 , p. $501-521,2014$.

\section{Pablo Cardozo Rocon}

pablocardoz@gmail.com

Bacharel em Serviço Social pela Universidade Federal do Espírito Santo (UFES)

Mestrando pelo Programa de Pós-Graduação em Saúde Coletiva na UFES

\section{Francis Sodré}

francisodre@uol.com.br

Doutora em Saúde Coletiva pela Universidade do Estado do Rio de Janeiro (UERJ)

Professora do Departamento de Serviço Social e do Programa de Pós-Graduação em Saúde Coletiva da Universidade Federal do Espírito Santo (UFES)

\section{Alexsandro Rodrigues}

xela_alex@bol.com.br

Doutor em Educação pela Universidade Federal do Espírito Santo (UFES)

Professor do Departamento de Teorias e Práticas Educacionais e do Programa de Pós-Graduação em Psicologia Institucional da Universidade Federal do Espírito Santo (UFES)

\section{UFES}

Departamento de Serviço Social

Av. Fernando Ferrari, 514

Goiabeiras - Vitória - Espírito Santo

CEP: 29075-910. 